\title{
Work Process and Hazard Analysis in Small-scale Gold Mining in Northern Philippines
}

\author{
Ana Marie R. Leung, $\mathrm{MD}^{1}$ and Jinky Leilanie $\mathrm{Lu}, \mathrm{MOH}, \mathrm{PhD}^{2}$ \\ ${ }^{1}$ Cordillera Administrative Region, Philippines \\ ${ }^{2}$ National Institutes of Health, University of the Philippines Manila
}

\begin{abstract}
Introduction. Small-scale mining (SSM) is mining by individuals, groups, families, or cooperatives with minimal or no mechanization, often in the market's informal (illegal) sector. According to the Mines and Geosciences Bureau (MGB) in the Philippines, the gross production value of small-scale mining as of the $1^{\text {st }}$ to $3^{\text {rd }}$ quarter of 2020 was 0.5 billion pesos (1.05 billion USD).
\end{abstract}

Objectives. This study investigated the work process in small-scale mining in the northern part of the Philippines. It documented the occupational hazards that small-scale gold miners are exposed to in each of the work processes.

Methods. The target population is a community in the northern Philippines where the majority of the males are engaged in small-scale gold mining. This qualitative study used work observation and hazards analysis tools to investigate small-scale miners' work processes and hazard exposures.

Results. The most widely employed mining technique in the target community is dog-hole mining consisting of several sub-processes: tunneling, ball milling, and gravity concentration, cyanide leaching, and smelting. The occupational hazards identified were noise exposure from the dynamite blast, temperature extremes, and exposure to dust from dynamite blasting. The small-scale miners were subjected to prolonged crouching and bending, handling tools, and carrying heavy sacks filled with mineral ores. The miners resorted to improvised protective equipment such as wearing sleeveless shirts and drinking water for temperature extremes, distancing themselves from the mining blasts during dynamite blasting, and intermittently used carts with manual handling to transport ores packed in sacks. In the ball milling and gravity concentration process, machine-related accidents such as cuts from the crusher were observed. In cyanide leaching, which uses massive amounts of cyanide, the most prevalent hazards were heat, dust, and chemicals such as cyanide fumes. The risks included smoke from burning ore and coal and exposure to borax and nitric acid fumes in the smelting process.

Conclusion. This study documented the work process in small-scale gold mining and the hazard exposures in this type of informal industry. It is suggested that the local and national governments implement intervention programs for occupational health and safety measures, and social security nets are provided for the small-scale miners in Itogon, Benguet.

Key Words: Small-scale mining, cyanide, dog-hole mining, occupational health and safety, gold extraction

\section{INTRODUCTION}

Small-scale mining (SSM) refers to mining by individuals, groups, families, or cooperatives with minimal or no mechanization, often in the informal (illegal) sector of the market ${ }^{1}$. According to the Mines and Geosciences Bureau (MGB) in the Philippines, the gross production value

Corresponding author: Jinky Leilanie Lu, $\mathrm{MOH}, \mathrm{PhD}$ National Institutes of Health University of the Philippines Manila 623 Pedro Gil St., Ermita, Manila 1000, Philippines Email: jdlu@up.edu.ph / jinky_lu@yahoo.com of small-scale mining in 2020 was P0.5 billion (USD 1.05 billion). ${ }^{2}$

Itogon is a municipality of Benguet Province in the Cordillera Administrative Region, Philippines. The majority 
of the people belong to the ethnolinguistic groups called Ibaloi and Kankanaey. Among these indigenous groups, the rudiments of small-scale mining are learned as early as the age of seven and passed on from generation to generation. In the seventies and eighties, the indigenous small-scale miners started using chemicals. Almost every miners' group has its ball mill and a cyanide leaching pad. ${ }^{3}$

Small-scale miners (SSMs) have been labeled worldwide as significant users of mercury and cyanide. Cyanide in high doses is highly lethal as it rapidly diffuses into tissues and binds to target sites within seconds. ${ }^{4}$ Hydrogen Cyanide $(\mathrm{HCN})$ can be easily absorbed from all routes of entry of exposure. ${ }^{5}$ Milder cyanide poisoning cases include headaches, nausea, vertigo, anxiety, altered mental status, tachypnea, hypertension, and the smell of bitter almonds in the patient's expiration. Most severe cases include unconsciousness, convulsions, cardiovascular collapse followed by shock, pulmonary edema, and death. ${ }^{5}$ Cyanide concentrations measured in the blood are usually inaccurately low. This is because cyanide has a very short half-life, and blood samples are rarely obtained within a short time.

Occupational health and safety among miners are lacking in most developing countries. ${ }^{6}$ In a study in Northern Nigeria, it was found that $100 \%$ of the miners were not using PPE and the quarry sites had no safety measures for the workforce. ${ }^{6}$ In another study in India, it was found among sandstone quarry workers that they were not using a face mask to prevent silica inhalation. ${ }^{6}$

This study looked into the work process, occupational hazards, and safety measures in a small-scale mining community in the northern Philippines. This gives a qualitative yet comprehensive understanding of the work process and the risks involved in such work.

\section{METHODS}

The target population for this study is the small-scale miners in Benguet province. The community comprises approximately 50 households where the adult males are engaged in small-scale gold mining as full-time workers. These males are young and in the prime of their lives. They handle cyanide and other chemicals used to extract gold. Females and children are also involved in SSM but to a lesser extent.

This study was observational and qualitative to elaborate on the research study paper in 2016. It is a detailed description of the work and hazards of small-scale mining in the target community through work analysis and qualitative hazard analysis. A group of medical doctors trained in occupational health undertook the work process and hazard analysis. Then an occupational health practitioner undertook the final validation of the work and hazard analysis in the target community. No interview was done for the observation process. Tools utilized through observation notes by trained medical doctors. The work process observation was done from the beginning with tunneling until the end, gold extraction. The hazard analysis covered physical, chemical, biological, and ergonomic hazards.

Five mining teams were observed at work while tunneling, two teams while ball milling, two during cyanide leaching, and one while smelting. These teams were the only miners present during the investigation as small-scale mining work is seasonal. These teams had a total of 32 miners. The data collection tool in this study included the work process observation and hazard analysis tools described earlier.

The study was approved by the now Research Ethics Board and registered with the Research Grants Administration Office of the University of the Philippines Manila.

\section{RESULTS}

\section{Results of the Work Process Observation}

\section{Work Process}

In Itogon, there were two types of living conditions: (1) relatively stable and organized housing among the miners who are permanent residents of the community and (2) crowded, less sanitary conditions in make-shift huts constructed either by permanent residents who build a second home nearer the mine sites or by transient migrant miners. There are several types of small-scale mining techniques. The most widely employed in Itogon is called dog-hole mining or panagusok. This type of small-scale mining involves several sub-processes: (1) tunneling, (2) ball milling and gravity concentration, (3) cyanide leaching, and (4) smelting. There is no work specialization as all the miners can perform all various tasks.

\section{Tunneling}

Tunneling involves digging a pathway or tunnel into the rock or earth under which the gold ore is believed to be located. The gold ore usually runs through the earth in veinlike formations. Miners determine the approximate location of the gold by observing the quality and contours of the land. Gold particles may also be traced to their source if these are washed down rivers and creeks.

The tunnels are blasted out of rock using dynamite. Further digging is done manually using handheld tools such as heavy mallets, chisels, shovels, etc. An ore sampling to determine gold content is done from time to time to determine the direction of further tunneling (Figure 1). The ore may be carried out of the tunnels using a cart on wheels called a bagon. Sacks of ore weighing approximately 50 kilograms are carried to the ball mill site on the miners' shoulders.

\section{Ball milling and gravity concentration}

Large ore fragments are crushed into small pieces measuring $2-3 \mathrm{~cm}$ in diameter. This is done by hand using a maso (mallet) for crushing and a baliwengweng (a hand-held 


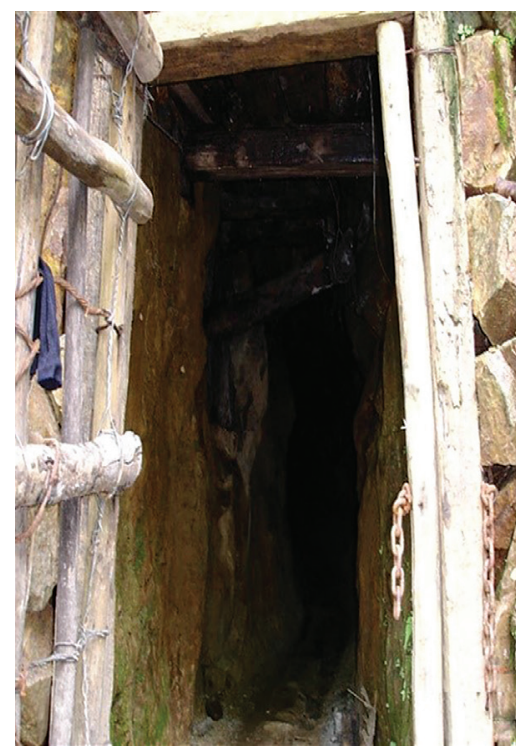

Figure 1. Tunneling Process in Small Scale Gold Mining.

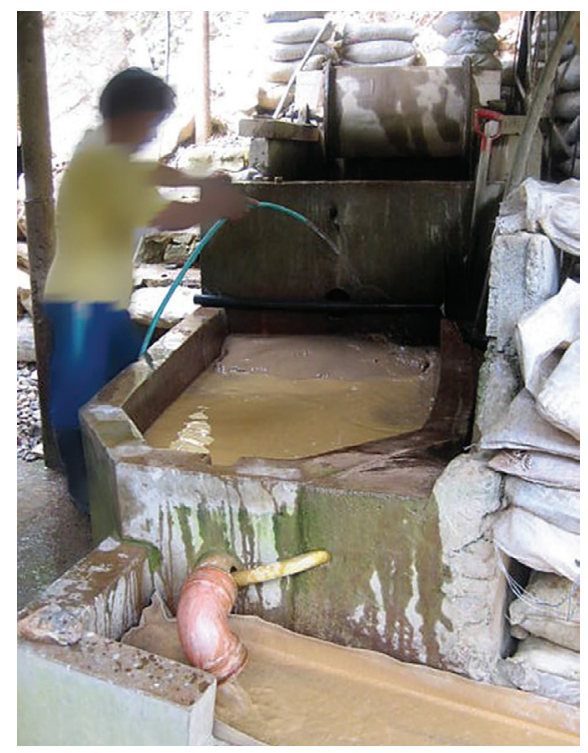

Figure 2. Ball Milling in Small Scale Gold Mining.

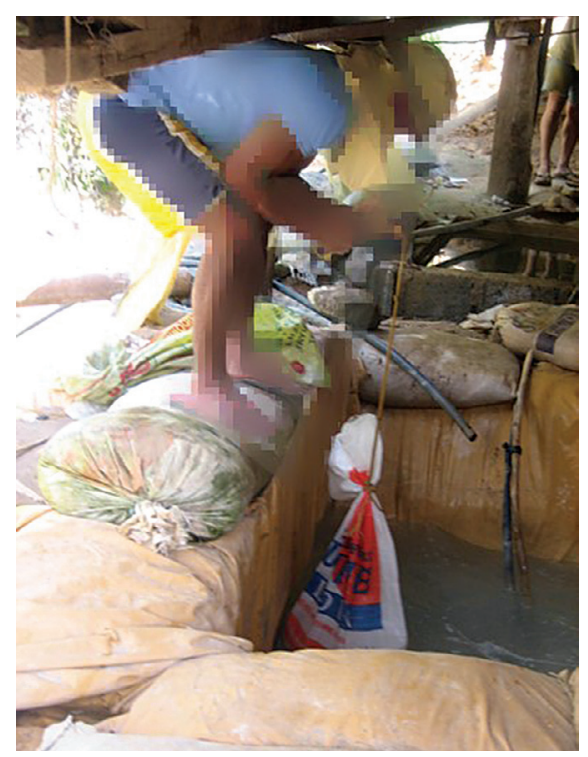

Figure 3. Dissolving the Cyanide. tool shaped like a big magnifying glass, with a wooden handle and a rubber loop attached) for holding the ore together while it is crushed. Pounding on the rock is done on a piece of stone or metal used as a platform (balbalan). The miners may also employ a crushing machine powered by electricity.

The ball mill is a rotating metal cylinder filled with steel rods. The crushed ore is fed into the ball mill, and water is added. A generator or electricity is used to rotate the metal cylinder. The rotation of the cylinder crushes the ore against the steel rods. Depending on the capacity of the cylinder, several sacks of ore can be ground at one time. The milling takes 2-3 hours. The product is of sand-like consistency. The sandy material is then made to pass through a series of wooden or cement chutes called barkis. The barkis is lined with jute sacks called $a p-a p$. The heavier gold particles stick to the $a p-a p$ as water continuously washes the sandy ore down the chutes. The gold particles are then washed off the jute sacks. These are collected in a big tub. The collected particles are then placed into a round metal pan. Through a circular motion, the gold particles are concentrated in the center of the metal pan. This process is performed repeatedly until most gold particles have been recovered (Figure 2).

\section{Cyanide leaching and Smelting}

The mine tailings or run-off that do not stick to the jute sacks is collected in a pit at the end of the series of chutes. The wet tailings are collected into bags. Later the sediments are placed in clumps on the ground to dry under the sun. When dried completely, the tailings are mixed with lime (calcium carbonate or $\mathrm{CaCO} 3$ ) in a ratio of 1 portion lime for every ten portions of tailings.

The lime-tailings mixture is first combined by shovel. Then it is passed through a mixing machine. As many as 200 sacks or more are mixed in this way for two days before the leaching pond is considered full. It is then time to prepare the cyanide solution. Every ten (10) kilograms of cyanide requires one (1) drum of water. About 40 kilograms of cyanide needs to be dissolved for mixing in the 200 sacks of tailings (Figure 3).

The cyanide is stored in a metal drum. It comes in solid pieces as large as ordinary bath soap. The solid cyanide is placed in a sack immersed in a pit of water, much like a teabag being dissolved in a pot of water. The cyanide solution is then siphoned into the cyanide pond and left to react for 5-6 days - the zinc-gold sticks to the lining of the precipitate bag as it passes through. The solution is passed through this process three times.

The precipitate bag is washed thoroughly with water. The solid precipitate is collected and then dried by heating over a fire. Pine coal (1-2 sacks total) is used as fuel, and an electric blower generates a fire with a higher temperature. The dried residue is then transferred to a clay pot, or gangi Borax (sodium borate) is mixed with the sediment in an amount equal to the amount of zinc dust used. The boraxprecipitate mixture is then heated at a high temperature.

The molten mixture is then quickly cooled in a basin of water. After cooling and solidification, the mixture is reheated in the clay pot. The molten mixture is poured into another bucket of water that is stirred continuously. Upon cooling, a black conglomeration of impurities separates and is discarded. The silvery particles left behind are again heated up. Nitric acid (about 1.5 liters) is added. The bottle of nitric acid is then discarded or washed in the nearby river (Figure 4). An orange vapor is emitted during this part of the process. Once again, the residue is combined with borax and re-heated to remove impurities further (Figure 5). A gold nugget is obtained (Figure 6). 


\section{Amount of time involved per sub-task}

Digging of tunnels or dog holes takes a few months to years. Ball milling takes 5-6 days to crush 200 sacks of ore. Sun-drying of ore takes 1-2 weeks. Mixing of dried ore

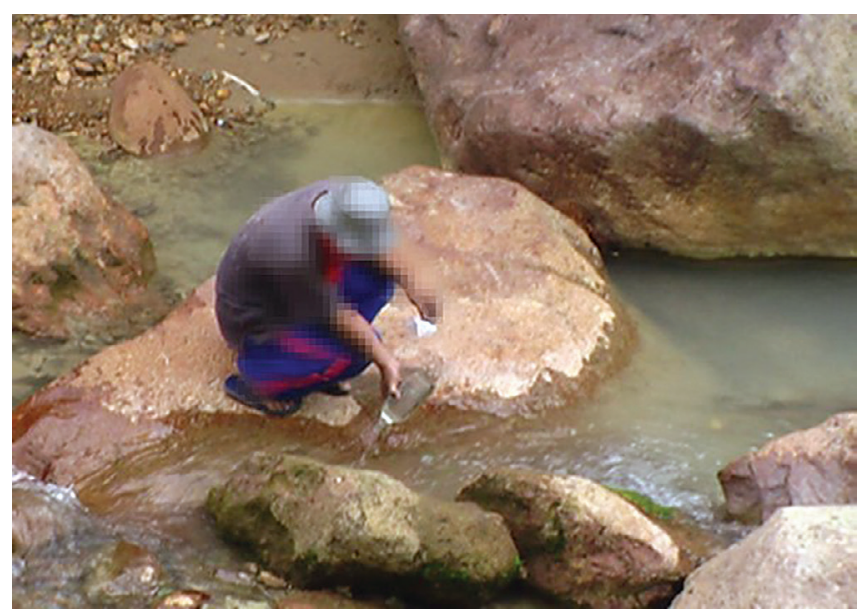

Figure 4. Smelting and Purification (Washing the Nitric Acid Container).

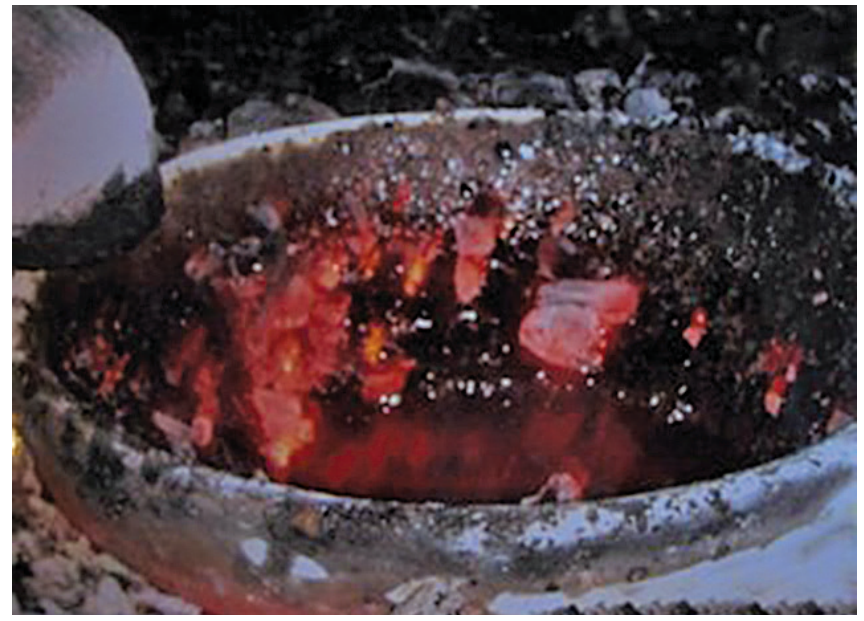

Figure 5. Smelting and Purification (Further Heating).

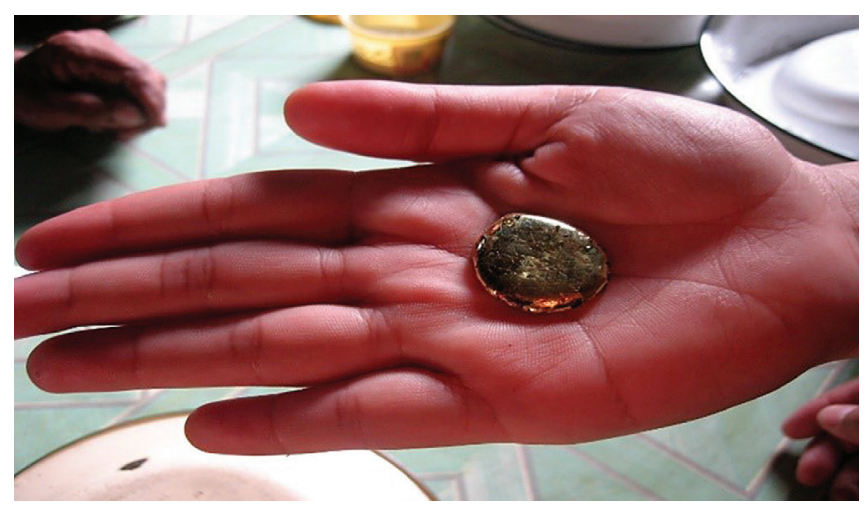

Figure 6. Smelting and Purification (Result: Gold). and lime to fill the cyanide pond takes two days. Cyanide leaching and precipitation with zinc dust take 5-7 days. Final smelting and purification take 7-8 hours.

\section{Worksite}

The tunnels are found in Surong and Tuap. Ball mills are located at many sites in the entire village. Cyanide leaching ponds are also located in many different areas, mainly along the Ambalanga River, across Sitio Dalisay. There can be as little as 5 meters between houses and cyanide leaching ponds. Smelting is done within residential areas. The mixing of nitric acid is done by the side of the river to put some distance between the houses and the fumes produced during mixing. However, the fumes were still observed to rise into vegetable and flower gardens above the River.

\section{Mine waste disposal}

The water used in washing the gold amalgam during smelting is poured directly into drainage canals running beside the houses. This water eventually ends up in the Ambalanga River that cuts across Sitio Dalisay. The bottle in which nitric acid is kept is washed directly in the river. After they have extracted all the gold, they can from it, the mine waste is dumped directly into the river. All the waste from Itogon SSM operations goes into the Ambalanga River.

\section{Occupational Hazards in the Work Processes}

The occupational hazards and sources of accidents were also identified among the groups of miners. Table 1 shows the specific dangers in the tunneling process that the miners were exposed to and the safety measures employed by the small-scale miners themselves. There was noise exposure from the dynamite blast, temperature extremes, exposure to dust from dynamite blasting. For ergonomics hazards, the miners experienced prolonged crouching and bending, long handling of tools, and carrying heavy sacks filled with mineral ores. There were no legal work protection and safety measures followed by the miners. They resorted to improvised protective equipment such as wearing sleeveless shirts and drinking water for temperature extremes, distancing themselves from the mining blasts during dynamite blasting, and intermittently used carts with manual handling in the transport of ores packed in sacks.

The miners were exposed to noisy ball milling and gravity concentration processes, but they undertook no noise protection measures. In this process, machine-related accidents were noted, such as experiencing cuts from the crusher. There were also particles from the crushing machine, but no goggles were worn (Table 2).

In cyanide leaching, which uses massive amounts of cyanide, the most prevalent hazards were heat, dust, and chemicals such as cyanide fumes (Table 3). In the smelting process, smoke from burning ore and coal and exposure to borax and nitric acid fumes were typical. Burn injuries were reported among miners (Table 3). 
Table 1. Occupational Hazards and Corresponding Safety measures Employed by the Small-scale Miners in the Tunneling Process

\begin{tabular}{|c|c|c|}
\hline $\begin{array}{l}\text { Type of } \\
\text { Hazard }\end{array}$ & Specific Hazard & $\begin{array}{c}\text { Safety Measures } \\
\text { Employed by the Miners }\end{array}$ \\
\hline \multirow[t]{3}{*}{ Physical } & Noise from dynamite blasting & Distancing from blast site \\
\hline & $\begin{array}{l}\text { Intermittent noise from } \\
\text { hammering }\end{array}$ & None \\
\hline & $\begin{array}{l}\text { Temperature extremes such } \\
\text { as heat }\left(28-30^{\circ} \mathrm{C} \text { inside the }\right. \\
\text { tunnels with poor ventilation) }\end{array}$ & $\begin{array}{l}\text { Wearing of sleeveless } \\
\text { shirt } \\
\text { Bringing of drinking } \\
\text { water }\end{array}$ \\
\hline \multirow[t]{3}{*}{ Chemical } & Dust & $\begin{array}{l}\text { Wearing of cloth or } \\
\text { handkerchief over the } \\
\text { mouth and nose }\end{array}$ \\
\hline & Dynamite blasting & $\begin{array}{l}\text { Distancing from the } \\
\text { blast site }\end{array}$ \\
\hline & Methane exposure & None \\
\hline \multirow[t]{2}{*}{ Biological } & Soil-transmitted infections & Wearing rubber boots \\
\hline & $\begin{array}{l}\text { Water-borne disease (espe- } \\
\text { cially during the rainy season) }\end{array}$ & Wearing rubber boots \\
\hline \multirow{8}{*}{$\begin{array}{l}\text { Ergonomic } \\
\text { and Safety } \\
\text { Risks }\end{array}$} & $\begin{array}{l}\text { Prolonged crouching and } \\
\text { bending }\end{array}$ & None \\
\hline & $\begin{array}{l}\text { Prolonged handling of tools } \\
\text { that are coarse and heavy }\end{array}$ & $\begin{array}{l}\text { Wearing gloves while } \\
\text { handling the tools }\end{array}$ \\
\hline & $\begin{array}{l}\text { Carrying heavy sacks filled } \\
\text { with ore }\end{array}$ & $\begin{array}{l}\text { Carts are used to } \\
\text { transport the ore }\end{array}$ \\
\hline & Falling rocks & Proper timbering \\
\hline & Cave-ins & None \\
\hline & Fall within vertical tunnels & Use of headlamps \\
\hline & $\begin{array}{l}\text { Repetitive muscular trauma } \\
\text { from mishandling tools }\end{array}$ & None \\
\hline & Blast injury & None \\
\hline
\end{tabular}

\section{Use of Personal Protective Equipment}

Head protection consisted only of bonnets and caps; no one wore a hard hat. Miners employed a handkerchief or piece of cloth as a mask during the dissolution of cyanide and while smelting. No one wore a respirator. Preferred clothing was a short-sleeved or sleeveless shirt and shorts. Only four miners wore long pants. Only three miners wore rubber boots. The rest wore slippers while working.

\section{DISCUSSION}

The task of extracting gold from the underground is a long and tedious process. The workplace condition of small-scale mining is often very hazardous and challenging. ${ }^{7}$ Small-scale mining methods such as gravity concentration in panning and sluicing pose health risks among workers. ${ }^{7}$ Furthermore, the nature of the work of small-scale miners is physically demanding and dangerous due to heavy workloads, unstable underground structures, non-ergonomically designed tools and equipment, exposure to dust and toxic chemicals, and extremes of temperature, and bad lightning. ${ }^{8}$ In addition to
Table 2. Occupational Hazards and Corresponding Safety measures Employed by the Small-scale Miners in the Ball Milling and Gravity Concentration Process

\begin{tabular}{|c|c|c|}
\hline $\begin{array}{l}\text { Type of } \\
\text { Hazard }\end{array}$ & Specific Hazard & $\begin{array}{c}\text { Safety Measures } \\
\text { Employed by the Miners }\end{array}$ \\
\hline \multirow[t]{3}{*}{ Physical } & Noise from the ball mill & None \\
\hline & $\begin{array}{l}\text { Immersion in water for } \\
\text { prolonged periods }\end{array}$ & Wearing rubber boots \\
\hline & Dust & None \\
\hline Chemical & Machine Oil & None \\
\hline Biological & Water-borne infections & Wearing rubber boots \\
\hline \multirow{7}{*}{$\begin{array}{l}\text { Ergonomic } \\
\text { and Safety } \\
\text { Risks }\end{array}$} & Heavy loads & None \\
\hline & Use of crude and heavy tools & None \\
\hline & $\begin{array}{l}\text { Machine-related accidents, } \\
\text { e.g., getting caught in the } \\
\text { crusher, ball mill fan belt, ball } \\
\text { mill cylinder }\end{array}$ & Machine guards \\
\hline & $\begin{array}{l}\text { Fall/drowning in the tailings } \\
\text { pond }\end{array}$ & No fence or rails \\
\hline & Electrocution & None \\
\hline & $\begin{array}{l}\text { Eye injury from particles } \\
\text { flying from the crusher }\end{array}$ & No eye protection \\
\hline & Slips on the wet, muddy floor & Wearing rubber boots \\
\hline
\end{tabular}

Table 3. Occupational Hazards and Corresponding Safety measures Employed by the Small-scale Miners in the Cyanide Leaching and Smelting Process

\begin{tabular}{|c|c|c|}
\hline $\begin{array}{l}\text { Type of } \\
\text { Hazard }\end{array}$ & Specific Hazard & $\begin{array}{c}\text { Safety Measures } \\
\text { Employed by the Miners }\end{array}$ \\
\hline \multirow[t]{3}{*}{ Physical } & $\begin{array}{l}\text { The heat from the } \\
\text { burning ore and coal }\end{array}$ & $\begin{array}{l}\text { Use of long tongs and ladle } \\
\text { for handling molten ore }\end{array}$ \\
\hline & $\begin{array}{l}\text { Smoke from burning } \\
\text { ore and coal }\end{array}$ & $\begin{array}{l}\text { The exhaust system leads } \\
\text { away from the work area (but } \\
\text { towards surrounding houses) }\end{array}$ \\
\hline & $\begin{array}{l}\text { The very bright flame } \\
\text { of burning ore and coal }\end{array}$ & No eye protection \\
\hline Biological & None identified & None \\
\hline Chemical & $\begin{array}{l}\text { Exposure to borax } \\
\text { and nitric acid }\end{array}$ & $\begin{array}{l}\text { Cloth mask } \\
\text { No gloves } \\
\text { Mixing with nitric acid done } \\
\text { away from the residences }\end{array}$ \\
\hline \multirow{2}{*}{$\begin{array}{l}\text { Ergonomic } \\
\text { and Safety } \\
\text { Risks }\end{array}$} & Burn injuries & Long-handled tools \\
\hline & Accidental poisoning & $\begin{array}{l}\text { Locking of storage cabinets } \\
\text { containing chemicals }\end{array}$ \\
\hline
\end{tabular}

this, the salary of small-scale miners is almost negligible. ${ }^{9}$ The work conditions among miners in Itogon are similar to those described for miners worldwide - lack of or limited use of mechanization, and a lot of physically demanding work; low level of occupational safety and health care; poor qualification of personnel at all levels of the operation; inefficiency in exploitation and processing of mineral production (low recovery value); exploitation of marginal, very small deposits or both, which are not economically exploitable by mechanized mining; low level of productivity; low level of 
salaries and income; periodic operation by local peasants by season or according to the market price development; lack of social security; insufficient consideration of environmental issues; and chronic lack of working and investment capital. ${ }^{1}$

In Itogon, the living conditions were either relatively stable and organized housing or crowded make-shift huts. The second type of housing is prone to the community health problems of poor sanitation and lack of clean water highlighted by the miners. ${ }^{10}$ The significant hazards identified in the small-scale mining areas, such as chemicals, dust, and ergonomic hazards, are similar to those identified by the miners. ${ }^{10}$ These are exposure to dust (silicosis), exposure to mercury and other chemicals, effects of noise and vibration; effects of poor ventilation (heat, humidity, lack of oxygen), and results of over-exertion, inadequate workspace, and inappropriate equipment identified the hazards in the workplaces in artisanal mining in Katanga. ${ }^{11}$

The hazards identified in this study were long crouching and bending, prolonged handling of tools, and carrying heavyfilled sacks with mineral ores. These ergonomic hazards arise from hand tools because small-scale mining uses rudimentary or primitive extraction techniques and employs an unskilled workforce. ${ }^{12,13}$ In another study, the identified ergonomic hazards were walking in a crouch position in underground mining, prolonged bending, and heavy lifting. ${ }^{14}$ Exposures to these risk factors can predispose a worker to injuries. A study among small-scale miners in Western Kenya identified that being subjected to awkward positions and constant bending/twisting increases their risk for injuries by 3.47 and 3.21 , respectively. ${ }^{15}$ Aside from hazards, safety practices are another injury risk factor. This study has shown that there were no legal work protection and safety measures followed by the miners. This is similar to a study in Ghana wherein the overall safety protective equipment was poor, and the common PPE used by the small-scale miners were merely hand gloves (27.1\%) and work boots (36.0\%). ${ }^{16}$

For the chemical hazard, the most common exposure is cyanide, especially among those involved in the cyanideleaching process of gold extraction. Cyanide is considered the most cost-effective method to extract bits of gold. To obtain an ounce of gold, 100 tons or more of the earth have to be removed. It is alarming to note the widespread use of cyanide among the Itogon miners with minimal personal protection. In contrast to mercury, few studies on the chronic effects of cyanide have been made. Quantities of hydrogen cyanide as small as a grain of rice $(50-200 \mathrm{mg}) \mathrm{can}$ be fatal. ${ }^{17}$

Meanwhile, improper waste disposal among the Itogon miners poses environmental risks. When cyanide is spilled into the environment in massive amounts, poisoning large bodies of water occurs. This occurred in Guyana in 1995, Kyrgystan in 1998, and Romania in 2000. ${ }^{25}$ This incident also happened in the Philippines, where a river in Benguet turned blue. The suspected cause was the unregulated use and disposal of cyanide. ${ }^{18}$
In the Philippines, several laws on the practice of smallscale mining have been instituted. Small-scale mining is governed by the RA 7076 (People Small-Scale Mining Act of 2021), passed in 1991 and aimed to generate and provide more employment opportunities in the mining sector. ${ }^{14}$ This law also created the "Minahang Bayan (people's mining community)," a designated area wherein small-scale miners can mine. ${ }^{19}$ Executive Order (EO) No. 79 was signed in 2012 that cleared conflicts and put the small-scale mining industry as a responsible sector. Under this $\mathrm{EO}$, previous mining laws were repealed. RA 7076 now is the governing legislation for the small-scale mining industry alone. Compression mining and mercury use were banned. The mining of natural resources was reduced to just gold, silver, and chromite. ${ }^{20}$ There is no law regarding banning cyanide in the Philippines, but it is controlled by DAO 1997-39, which regulates the use and disposal of cyanide in the Philippines.

For the miners themselves, legislations were also passed to protect the safety of the workers. DAO (DENR Administrative Order) $1997-30$ created the rules and regulations in small-scale mining. Under this $\mathrm{AO}$, safety inspections and training shall be provided for the SSM workers. ${ }^{19}$ While RA 11058 (An Act Strengthening Compliance with Occupational Safety and Health Standards and Providing Penalties for Violations thereof) aims to provide quality welfare and well-being to employees by preventing workplace-related accidents, deaths, injuries, and illnesses through the promotion of occupational safety and elimination of health hazards, actual improvements in smallscale mining safety and health are still to be seen. ${ }^{21}$

This study documented the small-scale mining work process and the hazard exposures in a small-scale mining community in the northern Philippines. This will serve well to show qualitatively and objectively the realities of small-scale mining work in this part of the country. This qualitative study shows the poor working conditions and hazard exposures of the small-scale miners in a locality in Benguet, which can serve as a basis for further quantitative studies for these groups of vulnerable working populations, as well as a rationale for policies and programs on occupational safety and health among miners. Its observational nature limits this study, and further studies should complement this. Likewise, only miners' work during the study time was looked into and did not include those not conducting mining since SSM is seasonal in this locality.

\section{CONCLUSION}

The small-scale miners of Itogon are a population of workers in the prime of their productive years. However, extracting gold from the underground is a long and tedious process that exposes the miners to various occupational and environmental hazards, with very little personal and industrial protection. 
With the health and safety of small-scale miners in the Philippines often overlooked and ignored, this study suggests a better focus on the said demographics as the industry is one of the contributors to both the local and national economies. The provincial government should implement intervention programs for occupational health and safety, and social security nets are provided for the small-scale miners in Itogon, Benguet.

\section{Statement of Authorship}

Both authors participated in the collection and analysis of data and approved the final version submitted.

\section{Author Disclosure}

Both authors declared no conflicts of interest.

\section{Funding Source}

This study was implemented through the National Institutes of Health, University of the Philippines Manila.

\section{REFERENCES}

1. Hentschel T, Hruschka F, Priester M. Artisanal and SmallScale Mining: Challenges and Opportunitie [Internet]. London: International Institute for Environment and Development and WBCSD; 2003 [cited 2020 Dec]. Available from: https://pubs.iied. org/sites/default/files/pdfs/migrate/9268IIED.pdf.

2. Mines \& Geosciences Bureau. Mining Industry Statistics [Internet]. 2020 Dec 1 [cited $2021 \mathrm{Feb}$. Available from: https://mgb.gov. ph/images/Mineral_Statistics/MIS_3Yr-2017_to_1st_to_3rd_ Qtr_2020_for_UPLOAD_as_of_14_Dec_2020.pdf.

3. Mines \& Geosciences Bureau. Mining Industry Statistics [Internet]. n.d. [cited $2021 \mathrm{Jul}$. Available from: http://www.mgb.gov.ph/Files/ Statistics/MinerallndustryStatistics.pdf.

4. Hamel J. A Review of Acute Cyanide Poisoning with a Treatment Update. Crit Care Nurse. 2011 Feb;31(1):72-82.

5. Lawson-Smith P, Jansen EC, Hyldegaard O. Cyanide Intoxication as Part of Smoke Inhalation - A Review on Diagnosis and Treatment from the Emergency Perspective. Scand J Trauma Resusc Emerg Med. 2011 Mar 3;19:14.

6. Babatunde OA, LM Ayodele, Elegbede OE, Babatunde OO, Ojo OJ, Alawode DA, et al. Practice of Occupational Safety among Artisanal Miners in a Rural Community in Southwest Nigeria. Int J Sci Environ Technol. 2013 Aug;2(4):622-33.

7. Ako TA, Onoduku US, Oke SA, Adamu IA, Ali SE, Mamodu A, et al. Environmental Impact of Artisanal Gold Mining in Luku, Minna, Niger State, North Central Nigeria. J Geosci Geomatics. 2014 Mar 5;2(1):28-37.

8. Dinye RD, Erdiaw-Kwasie MO. Gender and Labour Force Inequality in Small-scale Gold Mining in Ghana. Int J Res Econ Bus Manage. 2012 Nov;1(1):6-15
9. Bodenheimer M. Certifying Improvement, Improving Certification: An Analysis Based on the Artisanal and Small-Scale Mining Sector [Internet]. Karlsruhe: Frauhofer ISI; 2014 [cited 2020 Dec]. Available from: https://www.econstor.eu/bitstream/10419/ 101129/1/796237549.pdf

10. International Labour Organization. Social and Labour Issues in Small-Scale Mines (Report for Discussion at the Tripartite Meeting on Social and Labour Issues in Small-Scale Mines) [Internet]. Geneva: International Labour Organization; 1999 [cited 2021 April]. Available from: https://www.ilo.org/wcmsp5/groups/public/---ed_ dialogue/---sector/documents/meetingdocument/wcms_714371.pdf.

11. Elenge MM, De Brouwer C. Identification of Hazards in the Workplaces of Artisanal Mining in Katanga. Int J Occup Med Environ Health. 2011 Mar;24(1):57-66.

12. Mallo SJ. Mitigating the Activities of Artisanal and Small-Scale Miners in Africa: Challenges for Engineering and Technological Institutions. Int J Mod Eng Res. 2012 Nov-Dec;2(6):4714-25.

13. Elgstrand, K, Vingard E. Occupational Safety and Health in Mining Anthology on the Situation in 16 Mining Countries. Gothenburg: University of Gothenburg \& authors; 2013 [cited 2021 Feb]. Available from: https://gupea.ub.gu.se/bitstream/2077/32882/1/ gupea_2077_32882_1.pdf.

14. Granadillos NG, Parafina CS. Assessment of Occupational Safety and Health Hazards Exposure of Workers in Small-scale Gold Mining in the Philippines [Internet]. Philippines: International Labour Organization; 2020 [cited $2021 \mathrm{Mar}$ ]. Available from: https://www. ilo.org/wcmsp5/groups/public/---asia/---ro-bangkok/---ilo-manila/ documents/publication/wcms_751885.pdf.

15. Ajith MM, Ghosh AK, Jansz J. Risk Factors for the Number of Sustained Injuries in Artisanal and Small-Scale Mining Operation. Saf Health Work. 2020 Mar;11(1):50-60.

16. Nakua EK, Owusu-Dabo E, Newton S, Koranteng A, Otupiri E, Donkor P, et al. Injury Rate and Risk Factors among Small-scale Gold Miners in Ghana. BMC Public Health. 2019 Oct 24;19:1368.

17. Boulanger A, Gorman A. Hard Rock Mining: Risks to Community Health [Internet]. Montana: Women's Voices for the Earth; 2004 [cited $2021 \mathrm{Apr}$. Available from: https://www.sosbluewaters.org/ MiningHealthReport_WVE.pdf.

18. Cornes M. MGB Orders 8 mines Closed after Benguet River Turned Blue [Internet]. Manila: ABS-CBN Corporation; c2021 [updated 2017 Oct 16; cited $2021 \mathrm{Mar}$. Available from: https://news.abs-cbn. $\mathrm{com} /$ news $/ 10 / 16 / 17 / \mathrm{mgb}$-orders-8-mines-closed-after-benguetriver-turned-blue.

19. Mones MJ. Safety and Working Conditions in Small-scale Mining: The Case of Selected Small-scale Metallic Mines in the Philippines. Philippines: International Labour Organization; 2018 [cited 2021 Mar]. Available from: https://www.ilo.org/manila/publications/ WCMS_668736/lang--en/index.htm.

20. Philippine Council for Industry, Energy, and Emerging Technology Research and Development (DOST-PCIEERD). Green Mining Technology for the Small-Scale Mining Industry [Internet]. $2018 \mathrm{Mar}$ [cited $2021 \mathrm{Mar}$. Available from https://pcieerd.dost.gov.ph/images/ policy_advocacy/Policy-Brief-Mining-Itogon---PDF.pdf.

21. Bureau of Working Conditions (BWC-DOLE). Philippines: GOVPH; c2021 [cited 2021 Apr]. Rights to Safe and Healthful Conditions of Work; [about 5 screens]. Available from: https://bwc. dole.gov.ph/000076.html. 